f. med. Genet. (1969). 6, 411.

\title{
A Recessively Inherited Mixed Polyneuropathy of Early Onset
}

\author{
MOHSEN MAHLOUDJI
}

\author{
From the Department of Neurology, Nemazee Hospital, Shiraz, Iran
}

A family is described in which 3 sibs suffered from an unusual type of polyneuropathy which does not appear to have been reported before.

\section{Case Reports}

Case 1. A 17-year-old girl with the chief complaint of difficulty in walking. She was the product of an uneventful pregnancy and normal delivery at full term. She sat at 1 year but did not start to walk until the age of 4. From the start walking appeared awkward and she fell frequently, but she progressed slowly and when seen she could still walk quite easily without assistance. The patient had no complaints about her hands but on examination some changes were noted; other systems appeared normal. She had completed the 6th grade at school and had been an average scholar.

Physical examination showed a well-developed and well-nourished girl of average intelligence, with normal speech. Abnormalities were confined to the nervous system. The cranial nerves were intact: in particular the fundi were normal and there was no nystagmus. In the motor system no wasting was noted, but there was some hypotonia in the extremities. Grip was somewhat weak on both sides, and movements at the ankles were weak; otherwise no motor deficit was present. Co-ordination was good. All the tendon reflexes were absent. The abdominal superficial reflexes were also absent and the plantar responses were flexor. Touch sensation was lost in the hands up to the mid-forearm and in the lower extremities up to the knees. Pinprick and temperature sensations were diminished to the wrists and to the middle of the thighs. Vibration sense was lost up to the elbows in the upper limbs and up to the iliac crest in both lower limbs. Position sense was also impaired in the fingers and toes. Deep pain sensibility and stereognosis were intact. Romberg's sign was present and walking was ataxic; she could not keep to a straight line Nerve trunks were not enlarged on palpation. There was no deformity of the feet.

Investigations showed a normal chest $x$-ray, a 2-hour post-prandial blood sugar of $100 \mathrm{mg} . / 100 \mathrm{ml}$. Blood urea nitrogen of $11 \mathrm{mg} . / 100 \mathrm{ml}$., haemoglobin $14.7 \mathrm{~g} . /$ $100 \mathrm{ml}$., haematocrit $45 \%$, and white blood cell count of 5200, with a normal differential. Urine and stool examination showed no abnormalities. Venereal

Received December 3, 1968.
Diseases Research Laboratory (VDRL) test and Kahn were non-reactive. Total serum proteins were $7 \cdot 6 \mathrm{~g}$. with $\alpha / \gamma$ ratio of $4 \cdot 2 / 3 \cdot 4$; protein electrophoresis was normal. Cerebrospinal fluid (CSF) was under normal pressure and had a protein content of $82 \mathrm{mg} . / 100 \mathrm{ml}$, with no cells.

Biopsies from the gastrocnemius muscle and sural nerve were sent to Dr. Raymond D. Adams at Massachusetts General Hospital who reported as follows: 'a few large medullated sensory fibres are seen. Those remaining are small and are often embedded in tight clusters of connective tissues. The muscle shows some denervation atrophy. The findings are consistent with a polyneuropathy.'

Case 2. This patient was the $18 \frac{1}{2}$-year-old brother of Case 1 : his only complaint was occasional stumbling and falling since childhood. Pregnancy and delivery had been normal. He sat at 1 year but did not walk until 3 years. Walking was never normal; improvement had been noted with age. He was working as a shop assistant and attending night school, an average scholar.

Physical examination showed a healthy-looking boy with scoliosis of the thoracic spine. A supernumerary nipple was present on the right side. General examination showed no other abnormality. The cranial nerves were intact and the fundi normal. No wasting or loss of tone was noted. There was some weakness of dorsiflexion of both feet. All tendon jerks were absent, as were the abdominal superficial reflexes. The plantar responses were equivocal. Touch and superficial pain were diminished distal to the wrists and ankles. Temperature sense was impaired in the feet and in the fingers of the left hand. Vibration sense was defective distal to the ankles and position sense in the right toes. Deep pain sensibility was intact. Romberg's sign was present and he had some difficulty in keeping to a straight line on walking. Nerve trunks were not enlarged on palpation. The feet showed no deformity.

He was examined again 6 months later when there was, if anything, some improvement in muscle power. $\mathrm{He}$ attributed this to riding his recently acquired bicycle.

His haemogram, blood chemistry, serum proteins, electrophoresis, and serology were all normal. $X$-ray examination confirmed the scoliosis. CSF was under normal pressure, showed 2 lymphocytes, protein $138 \mathrm{mg}$. $/ 100 \mathrm{ml}$., and negative VDRL and Lange gold curve. 
Case 3. This 7-year-old girl was the sister of Case 1; she had walked at $2 \frac{1}{2}$ years, but gait was abnormal and she could not run. She did not co-operate in physical examination. The only abnormality noted was total absence of tendon reflexes.

\section{Family History}

The Figure shows the pedigree of the family. Both parents were alive and over the age of 40 . They were examined and found to be normal. They were first cousins. No other member of the family was known to suffer from the same or similar condition. Altogether there were 7 children, 3 boys and 4 girls. The remaining 4 children were normal.

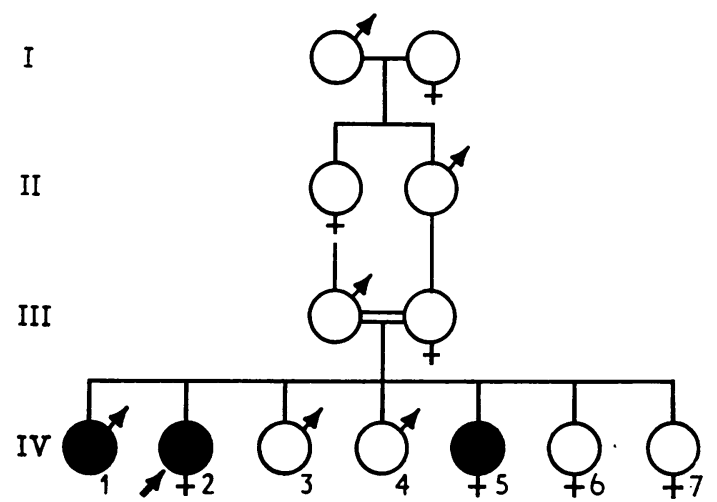

FIG. Pedigree of the family. Solid figures represent the affected members. Arrow points to Case 1 .

\section{Discussion}

The clinical picture in these patients is that of a very slowly progressive mixed polyneuropathy. The delay in motor milestones, in the absence of mental defect, shows that if not congenital the onset must be in infancy. The raised protein content of the CSF and the biopsy findings are nonspecific and in keeping with the clinical syndrome of polyneuropathy. The healthy parents and the consanguineous marriage point to an autosomal recessive mode of inheritance.

A sizeable number of hereditary polyneuropathies are on record (Ogden, Robert, and Carmichael, 1959; McKusick, 1966; Pratt, 1967) but none with features similar to the present family.
The closest is the hypertrophic interstitial neuritis of Dejerine and Sottas, but this syndrome has a later onset, atrophy of muscles, enlarged nerve trunks with characteristic histology, foot deformity, and an autosomal dominant mode of inheritance (Austin, 1956). In one patient with consanguineous parents (Symonds and Blackwood, 1962), the father and mother were not examined and the clinical and nerve biopsy findings were typical of hypertrophic interstitial polyneuritis. Curiously enough, this patient was said to come from Iran, but further inquiry (through Professor Roger Gilliatt) revealed that he was a resident of India. Recently Dyck and Lambert (1968) have presented some evidence in favour of recessive inheritance in the syndrome of Dejerine and Sottas, but all their patients had conspicuously enlarged nerves and a much more rapidly progressing course.

\section{Summary}

A family is described in which 3 sibs, 1 boy and 2 girls, suffered from a slowly progressive mixed polyneuropathy of early onset. The parents were first cousins. CSF protein was raised in the two cases examined, and nerve muscle biopsy in one showed changes consistent with a polyneuropathy. Review of the literature failed to show a similar re 8 port.

I wish to thank Dr. Rahim Dehghan for performing the biopsies and Dr. Raymond D. Adams for interpreting them.

\section{REFERENCES}

Austin, J. H. (1956). Observations on the syndrome of hypertrophic neuritis (the hypertrophic interstitial radiculoneuropathies). Medicine (Baltimore), 35, 187.

Dyck, P. J., and Lambert, E. H. (1968). Lower motor and primary sensory neuron diseases with peroneal muscular atrophy. I. Neurologic, genetic and electrophysiologic findings in hereditary polyneuropathies. Arch. Neurol. (Chic.), 18, 603.

McKusick, V. A. (1966). Mendelian Inheritance in Man. Catalogs of Autosomal Dominant, Autosomal Recessive, and X-linked Phenotypes. Johns Hopkins Press, Baltimore.

Ogden, T. E., Robert, F., and Carmichael, E. A. (1959). Some sensory syndromes in children: indifference to pain and sensory neuropathy. f. Neurol. Neurosurg. Psychiat., 22, 267.

Pratt, R. T. C. (1967). The Genetics of Neurological Disorders. Oxford University Press, London.

Symonds, C. P., and Blackwood, E. (1962). Spinal cord compression in hypertrophic neuritis. Brain, 85, 251. 